\title{
PODER E MULTICULTURALISMO
}

\author{
POWER AND MULTICULTURALISM
}

Carlos Alberto Simões de Tomaz ${ }^{34}$

Artigo recebido em: 20/11/2018.

Artigo aprovado em: 17/12/2018.

Resumo: A partir de uma análise crítico-descritiva, o artigo analisa o poder como fenômeno sociológico, político e jurídico. Divisa uma atuação hegemônica do poder por parte dos Estados líderes em defesa de uma identidade cultural unilateral imposta aos Estados periféricos, que se erige em detrimento das culturas locais, que se veem massificadas pelos efeitos da globalização. Aposta, em conclusão, no multiculturalismo guarnecido pelo princípio da subsidiariedade participativa em defesa da democracia e da efetividade da dignidade da pessoa humana.

Palavras-chave: poder; soberania; globalização, multiculturalismo; democracia.

Abstract: From a critical-descriptive analysis, the article analyzes power as a sociological, political and juridical phenomenon. It points to a hegemonic performance of power by the leading states in defense of a unilateral cultural identity imposed on the peripheral states which are massified by the effects of globalization. In conclusion, it bets on multiculturalism, which is guided by the principle of participatory subsidiarity in defense of democracy and the effectiveness of the dignity of the human person.

Keywords: power; sovereignty; globalization, multiculturalism; democracy.

\section{INTRODUÇÃO}

O destaque da agenda do terceiro milênio encontra-se, sem dúvida, na problemática dos direitos humanos. A preocupação com a efetividade dos direitos humanos e condições dignas de vida tem fervilhado aqui e alhures.

Nesse contexto, em face dos efeitos da globalização, busca-se divisar meios para afastar a global e unilateral massificação da identidade impingida pela cultura ocidental, buscando-se preservar valores e direitos a fim de ensejar uma globalização que seja homogênea, vale dizer, que respeite as identidades multicivilizacionais, não partindo, portanto, do falso suposto de hegemonia de uma cultura.

A partir daí, avulta-se de suma importância uma revisão teorética da concepção jurídico-política do poder. De fato, a presença e atuação de novos atores não-governamentais no cenário nacional e internacional

\footnotetext{
${ }^{34}$ Pós-doutor em Filosofia do Direito pela Universidade de Coimbra/Portugal. Doutor em Direito pela Universidade do Vale do Rio dos Sinos (UNISINOS). Professor da Universidade Vila Velha.
} 
tem deslocado o exercício do poder para outro eixo, desviando do tradicional sentido vetorial vertical como é tradicionalmente tratado na teoria política ou jurídica.

Essa nova atuação do poder ocorre em rede. É produto do que se convencionou chamar "sociedade em rede" e floresce no solo fértil do princípio da subsidiariedade-participativa.

Neste artigo, a partir de uma análise crítico-descritiva, o fenômeno do poder e o multiculturalismo serão analisados à luz de ideias traçadas por pensadores como Bobbio, Foucault, Habermas, Castells, entre outros, ao escopo de alvitrar elementos que possibilitem melhor compreender a nova constelação internacional em que vivemos.

\section{A COMPREENSÃO CLÁSSICA DO PODER COMO FENÔMENO POLÍTICO-JURÍDICO}

Talvez poucos tenham enfrentado tão bem o poder em sua concepção eidética como o fez SaintExupéry na famosa obra $O$ Pequeno Príncipe. Aliás, deste livro, que ganhou expressão na literatura mundial como uma fábula infantil e no campo da auto-ajuda para adolescentes e adultos, pode-se colher verdadeiras lições jurídico-políticas para os dias de hoje. No que pertine ao poder, recorde-se que o Pequeno Príncipe habitava sozinho um minúsculo planeta e bastava recuar um pouco a cadeira para contemplar o pôr-do-sol quantas vezes quisesse. O livro registra que o Pequeno Príncipe chegou a ver o sol se pôr quarenta e três vezes num único dia! E ao viajar, deparou-se o Pequeno Príncipe com um asteróide habitado por um rei sem súdito, mas que tinha pretensão de mandar no universo, que não hesitou um só instante em desferir um amontoado de ordens ao Pequeno Príncipe. Assim, divisou o Pequeno Príncipe que se ele fosse detentor de tanto poder, como aquele monarca que se dizia soberano do universo, teria podido assistir, não a quarenta e três, mas a setenta e dois, ou mesmo cem, ou mesmo a duzentos pores-do-sol no mesmo dia, sem precisar sequer afastar a cadeira! (SAINT-EXUPÉRY, 2002, p. 26.27 e 34-41). Sozinho no seu planeta, o Pequeno Príncipe não tinha em quem mandar. Iludia-se, pensando que mandava no sol e isso lhe satisfazia tanto que num só dia chegou a ver o pôr do sol quarenta e três vezes. É dizer, quarenta e três vezes pensou que mandou o sol se pôr, quando, na verdade, era o deslocamento de sua cadeira que ensejava a deflagração do movimento do planeta de modo a gerar dia e noite (explicação científica) e não a vontade do Pequeno Príncipe. Igualmente, aquele solitário monarca não mandava em nada. Satisfazia-lhe a ilusão de que reinava sobre o universo.

O autor deixa o leitor extrair a correta ideia de que o poder é inerente à natureza humana. Significa dizer: onde estiver o homem, aí haverá a manifestação do poder como fenômeno sociológico. Sim, o poder é obviamente um fenômeno social. E era exatamente por isso que nem o Pequeno Príncipe, nem o solitário monarca exerciam poder algum. Não havia em quem mandar. O poder, como fenômeno sociológico, é fundamentalmente uma relação entre dois pólos: um pólo de mando e um pólo de obediência. Essa relação 
social se projeta no plano vertical, não no plano horizontal. Horizontalmente, deixa de ser poder para ser cooperação.

No dia a dia, muitos se iludem como o Pequeno Príncipe e o rei solitário pensando que mandam e que são obedecidos. Na verdade, todos nós mandamos e todos nós obedecemos ao mesmo tempo. Considere-se, por exemplo, a relação de amizade entre duas pessoas. Por mais amigas que sejam, essa relação jamais se projetará horizontalmente, sempre um exercerá uma influência, ainda que mínima, sobre o outro, da mesma sorte que aquele que é influenciado com certeza influenciará outrem.

Impende, a partir daí, ou seja, considerando-se o poder como fenômeno social, verificar como a relação de mando e obediência se projeta dentro e fora do Estado. Deveras, para alguém poder deflagrar uma relação de mando e de obediência em nome do Estado é necessário que esteja investido de parcela de poder estatal. Esse alguém é denominado corriqueiramente de autoridade. $\mathrm{Na}$ linguagem jurídica, agente político, tipo especial de servidor público encarregado de manifestar a vontade em nome do Estado. A investidura, para tanto, ocorre sob as mais variadas formas: o rei, por exemplo, investe-se do poder do Estado, para deflagrar relações de mando e de obediência, pelo simples fato de ser o sucessor na linha de ascensão ao trono. Já nas repúblicas, as formas vão desde a escolha pelo voto, o concurso público ou a nomeação. Porém, não basta que alguém se encontre legitimamente investido para exercer o poder do Estado. É preciso, igualmente, que o exercício do poder se projete nos limites traçados pelo Direito. É dizer, em outras palavras, a autoridade, uma vez legitimamente investida, deve atuar no âmbito da legalidade, não devendo agir contra ou fora do espaço legal sob pena de agir com arbítrio ou desvio de poder em defesa da satisfação de interesse outros que não os eleitos pela norma.

Aí estão, portanto, os dois princípios nucleares da concepção democrática: legitimidade e legalidade, sem os quais não se concebe o exercício do poder na órbita do Estado.

O homem, quando nasce, já se encontra mergulhado na estrutura de poder do grupo primário: o poder de família que permite a tomada de decisões em relação a pessoa dos incapazes e de seus bens. Mas o homem começa a participar de grupos sociais secundários, onde são deflagradas novas relações de poder, como por exemplo, igreja, escola, associações econômicas, culturais, recreativas, de classe, sindicatos, partidos políticos. Então, existe, dentro do Estado, o poder da família, da igreja, das universidades, das corporações econômicas, dos times de futebol, da OAB, do CREA, dos sindicatos dos trabalhadores e da representação patronal, das várias opções políticas organizadas em partido, das federações, confederações, etc., etc. Mas há de haver um poder que se sobreponha a todas estas esferas de poder. Um poder que decida o conflito de interesse deflagrado entre o indivíduo e quaisquer grupos, dos indivíduos entre si e das próprias esferas de poder entre si. Desse poder, diz-se ser o poder de decisão em última instância, dentro do âmbito do Estado, que não admite poder maior nem igual a ele. Essa qualidade do poder do Estado é a soberania. 
A soberania, todavia, se projeta no plano externo. E aqui, ela pode ser encarada como a qualidade do poder do Estado de não admitir, no plano internacional, a existência de poder maior do que o poder estatal. Admite, tão apenas, poderes iguais.

Nessa perspectiva, vê-se que a soberania foi tomada como uma qualidade do poder do Estado, não como um elemento constitutivo, como defendem alguns, o que permite admitir a existência de Estados que conseguem expressar essa qualidade do poder em grau maior do que outros no plano internacional. Com efeito, do ponto de vista jurídico a norma de Direito Internacional Público vazada no princípio da igualdade entre os Estados propugna por que, repita-se, do ponto de vista exclusivamente jurídico, todos os Estados sejam igualmente soberanos porque gozam da mesma personalidade jurídica internacional, encontrando-se, portanto, igualmente capacitados para adquirir direitos e contrair obrigações. Por outro lado, enfrentada a questão sob o prisma político, militar, econômico, científico ou tecnológico, não há como não admitir que existam Estados que conseguem expressar em maior grau essa qualidade de seu poder ou, como se queira, Estados mais soberanos que outros.

O conceito de soberania tem, todavia, sofrido o impacto das mudanças que o mundo tem enfrentado nas últimas décadas do século passado e no início deste século. Deveras, não se pode mais concebê-la, como fez Kelsen (1992, p. 161), “apenas dentro do domínio do normativo”. Com efeito, a projeção desta qualidade do poder do Estado encontra-se entrelaçada em relações de hetero-referências partindo do sistema jurídico para o sistema social, político e econômico. Porém, um ponto merece reflexão: o mestre da Escola de Viena se mostra convencido quando aponta para a circunstância de que é pressuposto de uma posição monista com primazia do Direito Estatal sobre o Direito Internacional, a soberania absoluta do Estado. Sim, porque soberano seria apenas o "Estado cuja ordem jurídica fosse o ponto de partida de toda sua estrutura... O Direito Internacional é válido apenas por ser reconhecido pelo Estado mencionado em primeiro lugar, o qual é soberano porque a ordem jurídica internacional é considerada parte de sua ordem jurídica e, portanto, inferior a ela." (KELSEN, 1992, p. 373).

Sob tal contextura, e em face do predomínio do monismo com primazia do direito interno ou, quando menos do dualismo para ensejar a incorporação da norma internacional à ordem interna, a soberania ainda é encarada de forma absoluta, e isso, como se verá adiante, tem comprometido a fundamentabilidade dos direitos humanos e a atuação da comunidade e entes governamentais não-centrais em prol da dignidade da pessoa humana num mundo que se diz globalizado.

\section{O PODER HEGEMÔNICO E O FORTALECIMENTO DE UM ESTADO CENTRALIZADOR, BUROCRÁTICO E TECNOCRATA COMO TENDÊNCIAS EM DESCOMPASSO COM O IDEAL DEMOCRÁTICO}


Nessa linha de ideias pode-se dizer que o Estado, neste século XXI, palmilha por dois caminhos que, sem dúvida, podem distanciá-lo do eixo democrático. Divisa-se, com efeito, no plano externo, que a manifestação da soberania tem conduzido a posturas hegemônicas de Estados fortalecidos políticoeconomicamente em detrimento dos Estados periféricos. Por outro lado, no plano interno, a busca de eficiência e a administração dos escassos recursos disponíveis a guisa de se alcançar os objetivos previamente definidos, tem conduzido os Estados pelos passos de uma sensível centralização de poder aliada a uma política de redução de direitos historicamente incorporados ao patrimônio social. Ambos os fenômenos, como se disse, mostram-se inteiramente na contramão da perspectiva democrática.

O confronto funcional destas duas posturas enseja a seguinte indagação: pode existir ordem internacional democrática convivendo com Estados internamente não democráticos? A reposta requer o enfrentamento do poder hegemônico e das tendências da democracia diante do fenômeno da centralização tecno-burocrática do poder.

\subsection{O Poder hegemônico}

A dissolução da União Soviética rompeu com a bipolaridade do poder no cenário mundial. Com efeito, os EUA se consolidaram como o maior núcleo de poder que, sem concorrente, estabelece uma política internacional voltada para definir a atuação dos demais atores do cenário, imprimindo limites às experiências nacionais. Esse chamado unilateralismo norte-americano encontra-se fincado na crença da “universalidade da cultura ocidental”. Essa crença, amparada no crescimento ímpar da cultura ocidental, imprime a ideia de que em torno dela devem quedar outras culturas (as não-ocidentais), porque desviadas do eixo civilizatório adotado como padrão de globalização. Isso tem conduzido a uma política imperialista do principal Estado-núcleo da civilização ocidental, que não tem poupado esforços, inclusive com violação a princípios como o da autodeterminação dos povos, da não intervenção e do pacto de não-agressão, ao escopo de preservar a civilização ocidental ante uma expansão de outras culturas.

Com efeito, Huntington (2001, p. 396) registra a lição de Schlesinger Jr para quem entre os ocidentais, há o sentimento arraigado de que "as ideias de liberdade individual, democracia política, império da lei, direitos humanos e liberdade cultural (....) são européias, não são idéias asiáticas, nem africanas, nem do Oriente Médio, a não ser por adoção.”. Ora, é verdade que o berço do liberalismo e da democracia é a Europa. Deve-se, sem dúvida, ao pensamento político europeu a propagação pelo mundo dos ideais de liberdade, democracia e direitos humanos. Todavia, a adoção destes ideais não amesquinha em nada outras culturas, que se não os desenvolveram elas próprias, tal se deu em razão de que o desenvolvimento ocidental, sobremodo, da Europa, ocorreu em passos mais rápidos em comparação com as culturas asiáticas ou orientais, e em muito maior distância em relação à cultura africana. Aqueles ideais, contudo, não são 
privilégios da cultura ocidental. São inerentes à natureza humana. Devem ser entendidos, isto sim, como normas que integram o chamado ius cogens, de natureza, portanto, supraconstitucional e metacultural, que mais cedo ou mais tarde aflorariam no pensamento político de qualquer cultura. Coube à ocidental ser o carro-chefe da locomotiva.

Mas é em nome de uma expansão da cultura ocidental, eleita como a única apropriada para o desenvolvimento das potencialidades da pessoa humana, que tem se erigido o poder hegemônico, hoje concentrado nos EUA. A ação unilateral norte-americana não foi inicialmente cogitada quando do término da "guerra fria". De fato, chegou-se a pensar que com o fim da bipolaridade o mundo passaria para um clima de harmonia nas relações internacionais, com a vitória do capitalismo e da democracia liberal. Huntington (2001, pp. 32-33), descrevendo esta fase assevera que

\begin{abstract}
A expectativa de harmonia era largamente partilhada. Líderes políticos e intelectuais elaboraram opiniões similares. O muro de Berlim tinha caído, os regimes comunistas tinha desmoronado, as Nações Unidas iriam assumir uma nova importância, os antigos rivais da Guerra Fria se engajariam em "parceria" e numa "grande negociação", a ordem do dia seria a manutenção da paz e a imposição da paz. O presidente do país líder mundial proclamou a "nova ordem mundial"; o decano da que talvez se possa chamar a universidade mais importante do mundo vetou a nomeação de um professor de estudos de segurança porque sua necessidade havia desaparecido: "Aleluia! Não estudamos mais a guerra porque a guerra não existe mais. O momento de euforia no fim da Guerra Fria gerou uma ilusão de harmonia, que logo se viu não passar disso. O mundo ficou diferente no início dos anos 90 , mas não necessariamente mais pacífico. As mudanças eram inevitáveis, o progresso não. Ilusões semelhantes ocorreram, por breves períodos, ao final de cada um dos outros grandes conflitos do século XX. A I Guerra Mundial foi "a guerra para acabar com todas as guerras" e para tornar o mundo seguro para a democracia. A II Guerra Mundial, na colocação de Franklin Roosevelt, iria "pôr fim ao sistema de ações unilaterais, às alianças exclusivas, aos equilíbrios de poder e a todos os outros expedientes que tinham sido tentados durante séculos - e tinham fracassado sempre". Em vez disso, teríamos "uma organização universal" de "Nações amantes da paz" e o começo de uma "estrutura permanente de paz". No entanto, a I Guerra Mundial gerou o comunismo, o fascismo e a inversão de uma tendência de mais de um século rumo à democracia. A II Guerra Mundial produziu uma Guerra Fria que foi realmente global. A ilusão de harmonia no fim da Guerra Fria logo foi dissipada pela multiplicação de conflitos étnicos e de "limpeza étnica", pela ruptura da lei e da ordem, pelo surgimento de novos padrões de alianças e conflitos entre os Estados, pelo ressurgimento de movimentos neocomunistas e neofascistas, pela intensificação do fundamentalismo religioso, pelo fim da "diplomacia de sorrisos" e da "política do sim" nas relações da Rússia com o Ocidente, pela incapacidade das Nações Unidas e dos Estados Unidos de acabarem com sangrentos conflitos locais e a crescente disposição de afirmação de uma China emergente. Nos cinco anos seguintes à queda do Muro de Berlim, a palavra "genocídio" foi ouvida muito mais vezes do que em quaisquer cinco anos durante a Guerra Fria. O paradigma de um só mundo harmônico está claramente divorciado demais da realidade para ser um guia útil no mundo pós-Guerra Fria.
\end{abstract}

É nesse cenário que para o referido autor "o poder está-se deslocando da civilização ocidental que há tanto tempo predomina para civilizações não-ocidentais. A política mundial tornou-se multipolar e multicivilizacional." (HUNTINGTON, 2001, p. 29) Daí os esforços e ações de legitimação duvidosa do Estado líder mundial, com a cooperação de outros Estados-núcleos ocidentais como a Inglaterra, França e Alemanha, em defesa da expansão da cultura ocidental, ao escopo de reprimir a tendência multipolar e multicivilizacional, que revela um crescimento de Estados de culturas não ocidental ou não alinhados, a 
ponto de se cogitar de formação de novos núcleos de influência, como a China, até mesmo a Índia e o Brasil. Essa tendência, que tem empreendido ações conjuntas dos principais Estados-núcleos ocidentais e mais da Rússia, que se tem firmado como Estado-núcleo de influência no seu entorno, tem, não raro, sido fraturada como, por exemplo, quando da guerra do Iraque, ante a posição ostentada pela França e pela Alemanha, como também pela Rússia, o que ensejou a postura unilateral e hegemônica, sem precedentes, dos EUA em deflagrar a guerra sem a autorização da ONU. Aqui, mais uma causa da hegemonia do poder do Estado líder: a preocupação com a segurança mundial, que tem ensejado uma política de combate ao terrorismo, sobremodo depois da explosão das torres gêmeas, aliada à política desarmamentista nuclear.

A segurança e a paz mundiais, nessa contextura, passam a ser, a bem da verdade, sinônimo de segurança dos Estados-núcleos ou segurança do sistema sócio-econômico-cultural ocidental e, em sua defesa, não se tem poupado agressões à dignidade da pessoa humana.

Um mundo multipolar e multicivilizacional, com a possibilidade mais ampla de integração civilizacional, integrado por novos agentes que deslocam o eixo do poder antes exercido verticalmente e polarizado necessariamente pela vontade criadora e aplicadora do Direito monopolizada pelo Estado, parece ser o paradigma da resistência democrática, que encontra o ambiente propício quando se rompe esse monopólio e enseja o aparecimento e atuação de novos atores.

\subsection{O Estado centralizador, burocrático e tecnocrata. A expansão do poder ascendente e o princípio da subsidiariedade}

No plano interno, o exercício do poder revela que a democracia amarga frente a uma tendência enormemente centralizadora. Com efeito, o Estado moderno se viu diante de sérias dificuldades para atingir suas finalidades. A escassez dos recursos, a passagem de uma economia de mercado para uma economia globalizada, planificada, de difícil controle pelo processo de criação e aplicação normativa, sobretudo diante do aspecto multifacetário das relações de produção e consumo de bens e prestação de serviços, a concentração de riquezas, as políticas salariais, previdenciárias, assistenciais, em suma, tudo isso tem exigido do Estado bem administrar os escassos recursos, visando otimizá-los em defesa do desejável nível de bem-estar social de seus povos, o que não tem sido tarefa fácil.

Nesse espaço, lembra Bobbio (2002, p. 46) que

Tecnocracia e democracia são antitéticas: se o protagonista da sociedade industrial é o especialista, impossível que venha a ser o cidadão qualquer. A democracia sustenta-se sobre a hipótese de que todos podem decidir a respeito de tudo. A tecnocracia, ao contrário, pretende que sejam convocados a decidir apenas aqueles poucos que detêm conhecimentos específicos. Na época dos Estados absolutos, como já afirmei, o vulgo devia ser mantido longe das arcana imperii porque era considerado ignorante demais. Hoje o vulgo é certamente menos ignorante. Mas os problemas a resolver - tais como a luta contra a inflação, o pleno emprego, uma mais justa distribuição de renda - não se 
tornaram por acaso crescentemente mais complicados? Não são eles de tal envergadura que requerem conhecimentos científicos e técnicos em hipótese alguma menos misteriosos para o homem médio de hoje (que apesar de tudo é mais instruído)?

Isso tem determinado, segundo o festejado autor italiano, um "contínuo crescimento do aparato burocrático, de um aparato de poder ordenado hierarquicamente do vértice à base, e portanto diametralmente oposto ao sistema de poder democrático.” (BOBBIO, 2002, p. 47).

De fato, a experiência nos tem mostrado que as decisões, no mais das vezes, são tomadas sem a necessária vinculação à vontade dos governados; é que "o governo contemporâneo é cada vez menos um governo de leis, cada vez mais um governo de homens (...) grande parte das obrigações que pesam sobre o homem não resultam da lei ( ... ) provêm de atos 'com força de lei' editados pelo Executivo: Decretos-leis, leis delegadas, regulamentos autônomos, etc.” (FERREIRA FILHO, 1980, p. 13).

Talvez o acúmulo cada vez maior da função legiferante no poder executivo justifique-se em decorrência das necessidades prementes da atividade estatal em acompanhar o desenvolvimento por que passa o mundo moderno, e daí o ceticismo de alguns autores quando se debruçam na análise sobre o futuro do Estado. Shils, citado por Dallari (1980, p. 150), entre cinco espécies de sistemas políticos que apresenta, fundamentando-se na experiência dos Estados modernos do pós-guerra, é completamente descrente, e nenhuma de suas opções (Democracias Políticas, Democracias Tuteladas, Oligarquias Modernizantes, Oligarquias Totalitárias e Oligarquias Tradicionais) se coadunam com a concepção do Estado de Direito.

Ainda no tocante à questão, Dallari (1980, p. 164) afirma que "a racionalização objetiva implicando formas autocráticas de governo" é um dos caracteres futuríveis do Estado, mas ao lado disso vê a necessidade de uma "integração crescente do povo nos fins do Estado". E arremata: "Estas duas peculiaridades aparentemente opostas à primeira vista, deverão ser conjugadas para a obtenção de um novo equilíbrio interno".

Sem dúvida alguma este equilíbrio só se obtém quando, a par de todo o progresso científico e tecnológico, que inevitavelmente exige celeridade nas tomadas de decisão, levando cada vez mais a um racionalismo centralizado do poder, o Estado possibilita a existência de condições de igualdade, não de igualdade formal, mas de igualdade pragmática, alcançada quando o interesse propulsor da atividade estatal está voltado para o povo e não para a satisfação dos interesses de grupos dominantes. O poder deixa de ser um fim para ser um meio, um instrumento para consecução daquele fim.

Para fazer face a essa tendência, afirma Bobbio (2002, p. 67) que

...o processo de democratização, ou seja, o processo de expansão do poder ascendente, está se estendendo da esfera das relações políticas, das relações nas quais o indivíduo é considerado em seu papel de cidadão, para a esfera das relações sociais, onde o indivíduo é considerado na variedade de seus status e de seus papéis específicos, por exemplo de pai e de filho, de cônjuge, de empresário e de trabalhador, de professor e de estudante e até mesmo de pai de estudante, de médico e de doente, de 
oficial e de soldado, de administrador e de administrado, de produtor e de consumidor, de gestor de serviços públicos e de usuário, etc. (os destaques não são do original)

É sob o influxo desse novo eixo que começa a formulação teórica do princípio da subsidiariedade. A ideia parte, portanto, do fato de que o Estado não tem conseguido, por si, atingir as finalidades, os objetivos pré-estabelecidos, ensejando, em decorrência, a atuação popular organizada e voltada para auxiliar, subsidiar a atuação do Estado, senão mesmo substitui-lo em determinados campos de atuação. Abre-se, aqui, espaço para atuação de organizações não governamentais (ONGs), associações comunitárias, de empresas, igrejas, sem falar no próprio incentivo impingido pelos governos locais no auxílio para a definição de metas, tarefas, dispêndios e prioridades por meio de orçamentos participativos ou outros mecanismos de consulta.

Enfrentando as bases científicas que ensejam a formulação do princípio da subsidiariedade, Baracho (1995, pp. 103-104) assevera que:

\begin{abstract}
A elaboração teórica do Estado, aliada ao seu desenvolvimento na prática política, é resultante de etapas de seu desenvolvimento. As suas instituições básicas, sob o ponto de vista teórico e concreto, decorrem de anos de evolução política, tornando possível sua institucionalização. Essas circunstâncias demonstram a necessidade de uma revisão da própria estrutura do Estado. Estaria ela ultrapassada, tendo em vista a complexidade dos problemas econômicos, sociais, políticos e jurídicos. Não será ele, nos nossos dias, mecanismo de que não mais atende às grandes pressões sociais? As mutações estruturais e qualitativas da sociedade contemporânea, conduz a questionamentos sobre o conceito de "pluralismo". O pluralismo não é apenas uma maneira nova de afirmar a liberdade de opinião ou de crença. É um sistema que vincula a liberdade na estrutura social, não objetiva desvincular o indivíduo da sociedade. O pluralismo conduz ao reconhecimento da necessidade de um processo de equilíbrio, entre as múltiplas tensões na ordem social. O Estado pode chamar a si a tarefa de promover a decisão, assumindo, inclusive, a legitimidade do conflito. $\mathrm{O}$ poder do Estado não deve estar assentado em base unitária e homogênea, mas no equilíbrio plural das forças que compõem a sociedade, muitas vezes, elas próprias rivais e cúmplices. As democracias de poder aberto não podem aceitar o entendimento shmitiano de que os interesses da sociedade colidem ou são incompatíveis com os interesses superiores do Estado. A auto-organização da sociedade não exclui o princípio da unidade política, desde que a unidade que se procura, por meio do consenso, é a que se efetiva na pluralidade. A unidade na diversidade, não suprime a estrutura social muitas vezes antagônica. Os conceitos de consenso e pluralismo são categorias gerais, necessárias ao discurso político e normativo. A legitimidade do conflito decorre da integração dos corpos intermediários, através do consenso e da tolerância, propiciando o máximo de convivência comunitária. A multifuncionalidade do Estado contemporâneo conduz ao realce que vem sendo dado à relação entre Estado e Comunidade, principalmente nas sociedades onde ocorre sólida base comunal, propiciando maior interação entre o poder central e os poderes periféricos (federalismo, regionalismo, municipalismo). As alternativas da minoria à maioria, com os objetivos de renovação, o equilíbrio recíproco entre os diversos segmentos da sociedade, a alternância democrática, as novas e múltiplas variáveis introduzidas na Teoria da Constituição, apontam a qualidade constitucional que reside no sistema formal de distribuição orgânica das funções, mas também na interpretação de leitura coordenada dos conceitos de função, estrutura e processo, por meio de conclusões, sugestões e práticas renovadas." (destaques do original).
\end{abstract}

Sem dúvida, a expansão do poder ascendente sob os trilhos da subsidiariedade avulta-se um caminho para conter a tendência centralizadora, burocrática e tecnocrata do Estado em defesa do fortalecimento do ideal democrático. 
Está-se divisando, na linha de ideias ora expendidas, os caminhos que se apropriam a serem palmilhados pelo Estado em fortalecimento da democracia no terceiro milênio, bem como se apontando os empeços para uma convivência internacional mais fraterna.

\section{O EXERCÍCIO DO PODER EM REDE. A NOVA CONSTELAÇÃO. A ATUAÇÃO DE NOVOS AGENTES.}

Impende perceber que a concepção até aqui esboçada do poder como fenômeno político-jurídico, já focalizada dentro do multiculturalismo, encontra-se assentada na ideia de dominação presente entre dois pólos - o de mando e o de obediência - que deflagraria uma relação social verticalizada sem a qual inexistiria a relação de poder. No âmbito desta concepção, o Estado aparece no pólo de mando projetando a relação verticalizada, mas no sentido de cima para baixo.

Essa vetorização clássica da relação de dominação tem encontrado hodiernamente enfrentamento como se percebe das idéias de Bobbio para quem o poder tem se estendido da esfera das relações políticas para as relações em que o indivíduo aparece como centro de irradiação de vontade, naquilo que se tem chamado fenômeno da expansão ascendente do poder voltado para alterar o sentido do vetor.

A ideia, a bem da verdade, já se encontra esboçada em Foucault (2002, p. 184) quando assevera que

... o importante não é fazer uma espécie de dedução do poder que, partindo do centro, procuraria ver até onde se prolonga para baixo, em que medida se reproduz, até chegar aos elementos moleculares da sociedade. Deve-se, antes, fazer uma análise ascendente do poder: partir dos mecanismos infinitesimais que têm uma história, um caminho, técnicas e táticas e depois examinar como estes mecanismos de poder foram e ainda são investidos, colonizados, utilizados, subjugados, transformados, deslocados, desdobrados, etc, por mecanismos cada vez mais gerais e por formas de dominação global. (o destaque não é do original).

Para o renomado autor, a microfísica do poder implicaria numa opção metodológica onde

O poder deve ser analisado como algo que circula, ou melhor, como algo que só funciona em cadeia. Nunca está localizado aqui ou ali, nunca está nas mãos de alguns, nunca é apropriado como uma riqueza ou um bem. O poder funciona e se exerce em rede. Nas suas malhas os indivíduos não só circulam mas estão sempre em posição de exercer este poder e de sofrer sua ação; nunca são o alvo inerte ou consentido do poder, são sempre centros de transmissão. Em outros termos, o poder não se aplica aos indivíduos, passa por eles. (FOUCAUT, 2002, p. 193) (o destaque não está no original)

Dentro dessa linha de argumentação é possível afirmar que o fenômeno da expansão ascendente do poder, guarnecido sob o manto da subsidiariedade, propicia o exercício do poder em rede e tem se erigido em tendência para fortalecimento da democracia, ao passo que, ao mesmo tempo, impinge gravitação, que a depender da intensidade com que o fenômeno se desenvolva nas próximas décadas, terá o condão de senão desviar, ao menos suportar em melhores condições os efeitos irradiantes de núcleos hegemônicos de poder, 
sobretudo do Estado líder mundial. Com isso, não se pretende defenestrar a globalização, bandeira sob a qual se irradia a expansão da cultura ocidental, untada pelo fortalecimento de um capitalismo atroz, tendente a aniquilar o equilíbrio que deve haver no binômio capital $x$ trabalho. Definitivamente não! A globalização é fenômeno inevitável e irreversível.

Todavia, ajustar os Estados periféricos à globalização tem conduzido a uma situação de exclusão, onde a soberania popular e o princípio da dignidade da pessoa humana têm sido postos de lado em face da sobrepujança de um unilateralismo massificante. Em nome da globalização tem-se levado à falência pequenas e médias empresas nacionais a fim de propiciar a entrada de produtos dos países do primeiro mundo. Tem-se assistido a privatizações, entregando-se, sem controles, o poder e a riqueza de empresas estatais, o que tem acarretado consequências desastrosas para as relações de consumo. Tem-se reduzido os direitos sociais, especialmente os dos trabalhadores, aniquilando-se com a proteção à despedida arbitrária, reduzindo-se salários, amesquinhando-se aposentadorias, tudo em nome de uma reforma social. Assiste-se, ainda, a uma redução significativa de aporte de recursos do governo central aos governos locais, desfigurando-se federações e fazendo-se tábula rasa do princípio da subsidiariedade, prejudicando o desenvolvimento das regiões mais pobres. Os sistemas de saúde e de educação têm cada vez mais sua responsabilidade imputada aos governos locais ou à própria comunidade. Com isso, sucateiam-se escolas e hospitais. A carga tributária aumenta em nome de um pacto fiscal. Tudo, enfim, em defesa do que se preconizou chamar de "Reforma do Estado" ou "Modernização do Estado", ao escopo de preparar o Estado para enfrentar o terceiro milênio com um mundo globalizado.

Neste contexto, algumas perguntas se impõem: a que propósito tais medidas? Mascarariam objetivos outros? Avultam-se como o caminho adequado a ser palmilhado? O pesado sacrifício que se tem imposto aos povos periféricos pelos Estados-núcleos justifica-se em nome de uma globalização que propiciará a integração desses povos a um contexto comunitário internacional apto a garantir a dignidade da pessoa humana, a plenificação dos direitos fundamentais e o fortalecimento da democracia?

Há, sem dúvida, caminhos para a globalização ensejar desenvolvimento, bem-estar social, fortalecimento da vontade popular e, via de consequência, da democracia e em decorrência viabilizar a paz entre os povos, assegurar, enfim, em uma palavra, por mais paradoxal que possa parecer, inclusão. Sim, uma globalização de inclusão, com base teorética lastreada, entre tantos outros caminhos, pelos percorridos neste artigo, onde os benefícios de acesso ao desenvolvimento, à tecnologia, aos bens e aos serviços, possam ser estendidos aos povos dos Estados periféricos e experimentados por todos os indivíduos. Uma globalização que seja homogênea, vale dizer, que respeite as identidades multicivilizacionais, não partindo, portanto, do falso suposto de hegemonia de uma cultura. 
Enfrentando a globalização Habermas (2001, p. 84) assevera que utiliza o conceito "para a descrição de um processo, não de um estado final. Ele caracteriza a quantidade cada vez maior e a intensificação das relações de troca, de comunicação e de trânsito para além das fronteiras nacionais."

Esse processo enseja o que o referido autor convencionou denominar de nova constelação pósnacional, que revelaria o ambiente de mudanças onde o Estado nacional atua neste milênio. Esse ambiente impõe uma agenda de políticas públicas onde o Estado aparece tomando ciência que não mais detém o monopólio do direito, ante a atuação de antigos e novos atores num ambiente muito mais complexo e denso.

Firmando a atuação da sociedade em rede, prossegue Habermas (2001, p. 84) asseverando que:

\begin{abstract}
Assim como no século XIX o trem, o barco a vapor e o telégrafo intensificaram o trânsito de bens e das pessoas bem como a troca de informações, assim hoje em dia a tecnologia dos satélites, a navegação aérea e a comunicação digital criam novamente redes mais amplas e densas. "Rede" [Netzwerk] tornou-se uma palavra-chave, e tanto faz se se trata das vias de transporte para bens e pessoas, de correntes de mercadorias, capital e dinheiro, de transmissão e processamento eletrônicos de informações ou de circulações de pessoas, técnicas e natureza. Cadeias temporais comprovam as tendências globalizantes em muitas dimensões. O termo encontra igualmente aplicação na expansão intercontinental da telecomunicação, do turismo de massa ou da cultura de massa, bem como nos riscos transnacionais da técnica de ponta e do comércio de armas, nos efeitos colaterais mundiais do ecossistema explorado ou no trabalho conjunto internacional de organizações governamentais e não governamentais.
\end{abstract}

Todavia, a globalização tem imprimido uma legitimação do poder através de uma identidade imposta, padronizada e não-diferenciada como aponta Castells (2001, p. 25). Aliás, Castells mostra com precisão a expansão do poder em rede que revela, por outro lado, que "as atividades criminosas e organizações ao estilo da máfia de todo o mundo também se tornaram globais e informacionais, propiciando meios para o encorajamento de hiperatividade mental e desejo proibido, juntamente com toda e qualquer forma de negócio ilícito procurado por nossas sociedades, de armas sofisticadas à carne humana.” (2002, p. 40). Efetivamente, hoje divisa-se a existência de redes criminosas internacionais para tráfico de entorpecentes, órgãos, crianças, mulheres, armas, capital ilícito, etc.

\title{
5 CONCLUSÃO
}

É, sem dúvida, no cenário descortinado, que os indivíduos têm buscado se organizar sob o manto de fatores de identidade individual ou coletiva e, a partir daí, imprimido uma nova significação à globalização. O poder dessa identidade tem despertado a cada dia e tem se contraposto a uma identidade, como se disse, padronizada, imposta e não-diferenciada. O ambiente propício para o florescimento dessa identidade é o multiculturalismo, que se avulta como antídoto ao nivelamento de uma cultura dita ocidental. Castells, na série aqui já referenciada, tem se preocupado com a legitimação dessa identidade imposta pela globalização em descompasso com a identidade voltada para preservação de valores e crenças de movimentos em defesa 
de governos locais, comunidades indígenas, mulheres, homossexuais, meio-ambiente, etc. Semelhante trabalho tem sido desenvolvido por Boaventura de Souza Santos ${ }^{35}$.

O fato é que o poder dessa identidade vem sendo cultivado pelos novos atores como associações ou organismos não governamentais os mais variados, que da mesma forma que as redes criminosas, desviam o poder do eixo vetorial para imprimir uma atuação em rede. Essa atuação tem ensejado um rompimento dos limites entre o Direito Constitucional, o Direito Internacional e as Relações Internacionais na medida em que desviado o poder do eixo vetorial vertical, com a atuação em rede dos novos agentes, a soberania, conquanto ainda haja uma profunda assimetria em razão do poder econômico e do poder do próprio Estado, vê-se erigida em outras bases, quiçá legitimadas não pelo exercício de um poder hegemônico, mas pelo exercício de um poder em rede com maior participação da comunidade em defesa de interesses e valores.

Enfim, as veredas estão a vista... “...partes afastadas do mundo podem entre si estabelecer relações pacíficas, as quais por fim se tornarão legais e públicas, podendo assim aproximar cada vez o género humano de uma constituição cosmopolita.” (KANT, 1995, p. 137-138). A expansão ascendente do poder em rede, mercê de uma subsidiariedade-participativa, imprime o ritmo do vento em favor da democratização interna dos Estados. A tolerância sob o enfoque do respeito à diversidade cultural e da interação multicivilizacional, permitindo a aproximação e a interação entre comunidades, aliada a uma concepção aberta da soberania, desviada do eixo solipsista para propiciar cooperação, compartilhamento e integração em prol do desenvolvimento, enseja, também, o ambiente propício para desviar a órbita do poder hegemônico em defesa da dignidade da pessoa humana e coloca luz nos caminhos para a paz. Espera-se...

\section{REFERENCIAS}

BARACHO, José Alfredo de Oliveira. O Princípio da Subsidiariedade: conceito e evolução. In:

Desenvolvimento Econômico e Intervenção do Estado na Ordem Constitucional. Estudos Jurídicos em homenagem ao Professor Washington Peluso Albino de Souza". Porto Alegre: Fabris, 1995.

BOBBIO, Norberto. O Futuro da Democracia. 8a ed.São Paulo: Editora Paz e Terra, 2002.

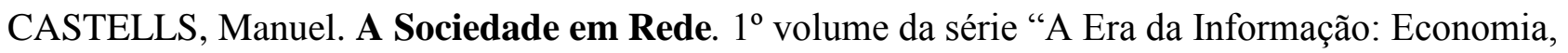
Sociedade e Cultura". 6ª ed., São Paulo: Paz e Terra, 2002.

CASTELLS, Manuel. O Poder da Identidade. $2^{\circ}$ volume da série "A Era da Informação: Economia, Sociedade e Cultura”. $3^{\text {a }}$ ed., São Paulo: Paz e Terra, 2001.

DALLARI, Dalmo de Abreu. O Futuro do Estado. São Paulo: Ed. Moderna, 1980.

\footnotetext{
${ }^{35}$ Consultar série Reinventar a Emancipação Social para novos Manifestos, sobretudo o $3^{\text {o }}$ volume intitulado Reconhecer para Libertar. Os caminhos do Cosmopolitismo Multicultural editado pela Civilização Brasileira, Rio de Janeiro.
} 
FERREIRA FILHO, Manoel Gonçalves. A revisão da doutrina democrática. Problemas Brasileiros, Revista Mensal de Cultura, ano XVII, nº 189. São Paulo: 1980.

FOUCAULT, Michel. Microfísica do Poder. Rio de Janeiro: Graal, 2002.

HABERMAS, Jürgen. A Constelação Pós-Nacional. Ensaios Políticos. São Paulo: Littera Mundi, 2001.

HUTINGTON, Samuel P. O Choque de Civilizações e a Recomposição da Ordem Mundial. Rio de Janeiro: Objetiva, 2001.

KANT, Immanuel. A Paz Perpétua e outros Opúsculos. Lisboa: Edições 70, 1995.

KELSEN, Hans. Teoria Geral do Direito e do Estado. São Paulo: Martins Fontes, 1992.

SAINT-EXUPÉRY, Antoine de. O pequeno Príncipe. Rio de Janeiro: Agir, 2002. 